\title{
A peek into the Future of Orthopedics: Computers and Artificial Intelligence!
}

\author{
Vikas Trivedi* \\ Department of Orthopaedics, Era's Lucknow Medical College, India \\ Submission: February 01, 2018; Published: February 28, 2018 \\ *Corresponding author: Vikas Trivedi, Department of Orthopaedics, Era’s Lucknow Medical College, India, Email: drorthovt@hotmail.com
}

\section{Opinion}

Computers, smart phones, smart homes and self -driven cars have already been involved in our daily lives not to mention those computers which are flying airplanes, directing trains and operating drones. Now, Supercomputers are beating humans in chess and solving the most complex problems in a millionth of a second. As we tweet or Google anything on web, the Artificial Intelligence (AI) machines are reading our mind and quietly slipping advertisements into our webpages as per our selections!

The technological barriers are overcome too easily now and the days are not far that computers may be able to diagnose diseases and perform surgery! Orthopedic surgery is one of the first specialties to get influenced by this change and it lends itself to robotic surgery because the bones and soft tissue that orthopedic surgeons treat are relatively easy to image accurately. Human surgeons have so far made all of the decisions about what treatments patients need and how to go about them, using robots only to execute these decisions in circumstances requiring special dexterity, precision, or stamina. How long before a computer equipped with such precise detailed image information can control its own mechanical arm to, for example, locate, align, and fix a broken bone?

\section{Computer-Assisted Navigation Currently Used in Orthopedics}

Orthopedic surgeons have used robots since the 1990s, but recent advances are making the machines more useful. In their simplest forms, robots can act as guides to help surgeons position screws, prostheses, or tunnels. For example, the Optotrak 3020 (NDI Measurement Sciences) uses infrared light to locate bones intraoperatively. Similarly, the Robodoc (Curexo Technology) mills the canal for a prosthesis using prepared surgical plans based on CT scans.

In Total Hip replacement Surgery, computer assistance in placing the cup of the prosthesis has proved more accurate than conventional methods. Other robots have used CT to provide a real-time virtual model of the surgical field. Some use haptic technology to provide the surgeon controlling a robotic arm with a virtual sense of touch (Tele Manipulator) [1].

In the Knee Replacement Surgery, robots also assist with alignment of prostheses and with minimally invasive surgery. In Arthroscopic Surgery, Robots are able to position tunnels in the femur or tibia more accurately than surgeons using conventional means, potentially reducing the risk for revision of anterior cruciate ligament reconstruction [1]. Computer-aided navigation is proving useful in shoulder arthroplasty or where normal anatomy is distorted, such as with fractures, revisions, and glenoid wear or dysplasia [1].

In the spine, computer-assisted navigation helps surgeons avoid neurovascular structures, and its role is well established in the placement of thoracic and lumbar pedicle screws. The incidence of misplaced screws is as high as $42 \%$ with traditional surgical techniques, according to some studies, but it is only $10 \%$ with computer assistance. Robotic surgery does still have its major downsides. Notably, it takes longer to complete the procedures, raising the cost and the risks from anesthesia. But in the spine, at least, the consensus is emerging that the improved accuracy merits the extra cost [2].

\section{Artificial Intelligence for Analyzing Radiographs}

A team of researchers at Karolinska Institutet, Danderyd Hospital, and the Royal Institute of Technology in Stockholm, Sweden recently developed an artificial intelligence system for reading radiographs [3]. To teach computer networks to read radiographs, they fed them 256,458 hand, wrist, and ankle radiographs with labels stating whether or not the images contained fractures, the body part, laterality (left or right), exam view (anteroposterior/frontal, lateral, or oblique [two different types]), and four scaphoid-specific views (proximal, distal, ulnar, and radial). Fifty-six of the images contained fractures. For fractures, the best computer network had an accuracy of $83 \%$ in identifying fractures in these images. By comparison, the human reviewers were accurate $82 \%$ of the time (Figure 1 ). 


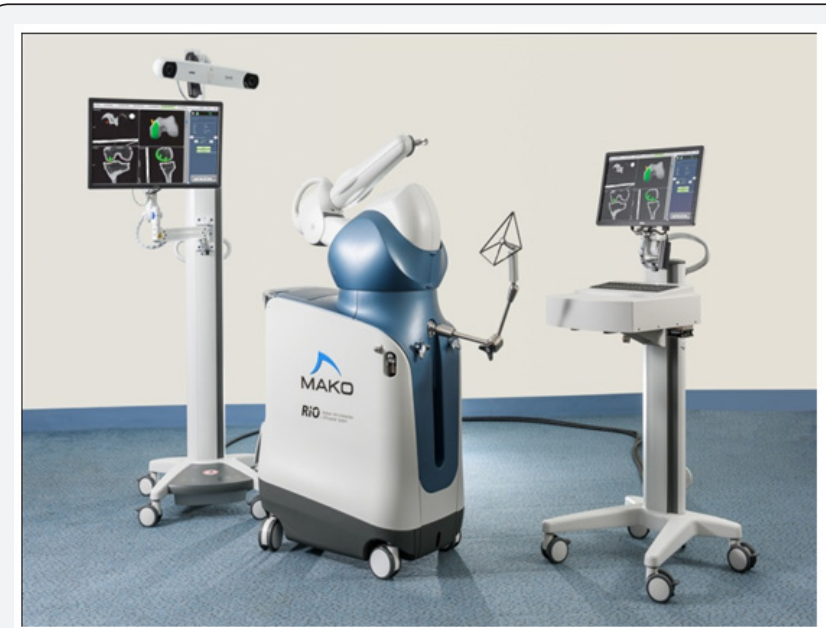

Figure 1: Computer-aided navigation.

On another subset of images, the computer networks reached an accuracy of $99 \%$ on body part, $95 \%$ on exam view, and $90 \%$ on laterality. This is exactly human-level performance. More than $80 \%$ of orthopedic surgeons' clinical decisions are made on the basis of radiographs; the next step would be for artificial intelligence systems to use images to quantify risk, perhaps telling one patient that a knee replacement has an $80 \%$ chance of eliminating the pain and telling another that the procedure has a $50 \%$ chance.

\section{Will Orthopaedic Surgeons be Replaced by Robots in Future?}

Patients have so far shown great interest and enthusiasm for surgery assisted by robots, dazzled by the high-tech sophistication. I feel patients would still like humane orthopedic surgeons be around them during the treatment process, Already, orthopedics has the reputation of a "high-tech, low- touch" profession that needs to work on bedside manners. A large component of the physician/patient relationship, even for surgeons, is the communication and the relationship, and that absolutely would be lost if artificial intelligence starts to makes all the clinical decisions along with, or for the patient and then also performs the surgery. There will be legal ramifications as even the best robot guided by the best artificial intelligence will make mistakes. Then who will be liable? A surgeon who is nominally supervising the procedure or the manufacturer of the robot? Some of the biggest barriers may come from surgeons themselves as we still have the option in many settings to refuse technology that could replace us. The near-term future of surgery may more closely resemble that of an airplane flight, "The airline pilot is there to assist in terms of landing and flying a plane, but the instruments are able to do a very large amount of the work." Robotics and Artificial intelligence will be always there in future and I feel a synergistic relationship between the creative human mind and them is the way forward for effective care of our patients.

"The True Sign of Intelligence is not Knowledge but Imagination"

\section{Albert Einstein.}

\section{References}

1. Hernandez D, Garimella R, Eltorai AE, Daniels AH (2017) Computerassisted orthopaedic surgery. Orthop Surg.

2. Watkins RG, Gupta A, Watkins RG (2010) Cost-effectiveness of imageguided spine surgery. Open Orthop J 4: 228-233.

3. Jakub Olczak, Niklas Fahlberg, Atsuto Maki, Ali Sharif Razavian, Anthony Jilert, et al. (2017) Artificial intelligence for analyzing orthopedic trauma radiographs: Deep learning algorithms-are they on par with humans for diagnosing fractures? Acta Orthopaedica 88(6): 201.

\section{Your next submission with Juniper Publishers will reach you the below assets}

- Quality Editorial service

- Swift Peer Review

- Reprints availability

- E-prints Service

- Manuscript Podcast for convenient understanding

- Global attainment for your research

- Manuscript accessibility in different formats

( Pdf, E-pub, Full Text, Audio)

- Unceasing customer service

Track the below URL for one-step submission https://juniperpublishers.com/online-submission.php 